\title{
Correlation between Anxiety and Personality in Caregivers for Patients with Schizophrenia
}

\author{
Enver Demirel Yilmaz ${ }^{1^{*}}$, Erdem Deveci ${ }^{1}$, Hüseyin Güleç ${ }^{2}$, Ali Görkem Gençer ${ }^{3}$, Özge Ünal ${ }^{4}$, Emel Koçer ${ }^{1}$ and İsmet Kirpinar \\ ${ }^{1}$ Department of Psychiatry, Faculty of Medicine, Bezmialem Foundation University, Istanbul, Turkey \\ ${ }^{2}$ Department of Psychiatry, Erenköy Training and Research Hospital for Psychiatric and Neurological Diseases, Istanbul, Turkey \\ ${ }^{3}$ Department of Psychiatry, Başakşehir State Hospital, Istanbul, Turkey \\ ${ }^{4}$ Department of Psychiatry, Istanbul Education and Research Hospital, Istanbul, Turkey
}

*Corresponding author: Enver Demirel Yılmaz, Department of Psychiatry, Faculty of Medicine, Bezmialem Foundation University, Adnan Menderes Avenue 34083 Fatih/Istanbul, Turkey, Tel: +9 021245317 00; Fax: +9 021262175 80; E-mail: enveryilmaz6@yahoo.com.tr

Received date: March 03, 2014; Accepted date: June 9, 2014; Published date: June 18, 2014

Copyright: (C) 2014 Yilmaz ED, et al. This is an open-access article distributed under the terms of the Creative Commons Attribution License, which permits unrestricted use, distribution, and reproduction in any medium, provided the original author and source are credited.

\begin{abstract}
Objective: The objective of this study is to analyse the correlation between state and trait anxiety, depression and personality traits in caregivers of patients diagnosed with schizophrenia.

Method: The study sample consists of care-givers of 34 patients diagnosed with schizophrenia according to the DSM IV-TR criteria and 37 healthy voluntary subjects that are demographically matched. The Temperament and Character Inventory (TCI), Hamilton Depression Rating Scale (HDRS) and State-Trait Anxiety Inventory (STAIX I-II) scales were applied to the subjects.

Results: In this study, it has been found that STAIX-I and STAIX-II anxiety scores are higher among caregivers. The comparison between the groups has revealed that persistence $(P)$ scores are higher in caregivers $(P=0.036)$. $A$ statistically significant correlation has been found between the STAIX $-I$ score and harm avoidance (HA) ( $r=0.64$, $P<0.001)$; self-transcendence (ST) $(r=0.44, P=0.01)$ and self-directedness (SD) scores $(r=-0.58, P<0.001)$; STAIX-II score and harm avoidance $(H A)(r=0.62, P<0.001)$; self-transcendence (ST) $(r=0.47, P=0.005)$ and self-directedness (SD) scores $(r=-0.58, \mathrm{P}<0.001)$ of $\mathrm{TCl}$.
\end{abstract}

Conclusion: Our results suggest that, considering their personal traits, caregivers of patients with schizophrenia should be assessed by clinicians more carefully and comprehensively in respect of anxiety.

Keywords: Schizophrenia; Caregivers; Anxiety; Temperament; Personality; Depression

\section{Introduction}

Schizophrenia is a chronic psychiatric disorder causing common disability. The disorder seriously affects caregivers as well as patients. Besides living with and experiencing psychiatric symptoms of the patient, both physical and psychiatric burdens of the disorder psychologically affect caregivers. Most of the patients live with their families, and families undertake the role of providing care without getting any external professional support [1]. Psychological distress emerging in patients' relatives naturally induces adverse impacts in the treatment process. As treatment process of the psychiatric disorders change, a society-based model is being accepted. Therefore, the progression of the disease results in extended periods spent within the family beyond inpatient treatment institutions, requiring the families to assume a more active role in the treatment of the patients. Therefore, there is a growing interest for the correlation between the progression of the disease and behaviour of caregivers [2].

The contribution of patient's relatives to the treatment of chronic psychiatric disorders is indisputable. The common acceptance is that patient relatives represent one of the leading decisive factors in continuing or suspending the treatment [3]. The care-giver is one of the three key components of the overall treatment process alongside the patient and the healthcare team. Ultimately, cooperation with patient relatives is of crucial importance in the process of the treatment.

Interviews with caregivers of schizophrenia patients usually include negative expressions. Aspects related to the unique progression of the disease, disturbing patient behaviours, isolation, poor support of the family members, limited reciprocity in relationships with the patient, distress of losses suffered by the patient and physical violence are the issues reported most frequently by caregivers [4,5]. Care giving not only causes financial loss, but also requires energy and time consumption. At the end of this process, the patients feel guilt, anger and depression.

In order to identify the behaviours of individuals, it is important to understand the role of personality traits. Personality traits may play a deterministic role in transformation of objective burdens of care giving for chronic psychiatric diseases like schizophrenia to subjective burdens like depression or anxiety. However, there is a limited number of studies in the literature related with the role of personality traits of caregivers and anxiety. This study considers the contributions of caregivers in diagnosis and treatment process as well as ensuring the adaptation of patients to the environment. This research aims to analyse the correlation between state and trait anxiety, depression 
severity and personality traits in caregivers of patients diagnosed with schizophrenia. While many of the studies in the literature include data about patient burden, stigmatization, expressed emotions and development of depressive symptoms in caregivers [6-8], the present study rather focuses on the anxiety conditions and personality traits of caregivers.

\section{Materials and Methods}

This study is conducted as a part of the research to better comprehend the burden of patient relatives of psychiatric disorders with chronic progression. The sample group participating in the study is composed of caregivers of 34 patients diagnosed with schizophrenia according to the DSM IV-TR criteria under treatment at the psychiatry clinic and 37 voluntary subjects among hospital staff that demographically matched with patient relatives. Inclusion criterion of caregivers in this study is being literate. Exclusion criteria for caregivers are being under psychiatric treatment, having a history of chronic diseases (diabetes mellitus, chronic heart disease, chronic renal failure, asthma, thyroid disorders, etc.), and taking active medication. At the stage of building up the sample group, a total of 75 people were screened, whereby 4 people were excluded and 71 were admitted to the study. Ethical approval of the study is assessed by the Education Planning Committee and necessary permissions were obtained. Written informed consent was received from all subjects.

\section{Materials}

Sociodemographic Data Sheet, State and Trait Anxiety Inventory (STAIX I-II), and Temperament and Character Inventory (TCI) were applied to all subjects. These inventories are self-assessment inventories. In addition, the Hamilton Depression Scale (HDRS) was applied to the subjects.

Cloninger's Temperament and Character Inventory (TCI): This is a self-assessment inventory developed by Cloninger. The inventory consists of 240 "TRUE or FALSE" questions [9]. The validation and reliability of the Turkish version of TCI was prepared by Köse et al. [10].

Hamilton Depression Rating Scale (HDRS): This scale was developed by Max Hamilton and updated by Janet Williams [11]. It measures the level of depression and alterations of its severity. It is made up of 17 items. A score of 14 or above suggests depression. The validation and reliability of the Turkish version was prepared by Akdemir et al. [12]. The practitioner's knowledge of psychopathology is significant in application of this scale.

Spielberger's State Trait and Anxiety Inventory (STAIX I-II):This inventory, developed by Spielberger et al. is composed of two subscales, namely state and trait, each consisting of 20 questions [13].

1. State Anxiety Scale (STAIX I): Identifies how the individual feels himself/herself at a certain time and at particular conditions.

2. Trait Anxiety Scale (STAIX II): Identifies how the individual feels himself/herself independently from his/her present state and condition. It is a simple self-inventory. It has been adapted to Turkish by Öner [14].

\section{Statistical analysis}

The conformity of data with normal distribution was analysed by using the Kolmogorov Smirnov test. The chi-square test was performed for the comparison of demographical and clinical variables between the groups, and the Student $t$ test was performed for continuous variables. Correlation of TCI sub-scales with STAIX I-II and HDRS data was carried out by means of the spearman correlation analysis. The data were presented in average \pm standard deviation and $\%$. The statistical significance limit was assumed as $\mathrm{p}<0.05$.

\section{Results}

Of 34 caregivers participating in the study, $41.2 \%$ are female in an average age of $41.76 \pm 14.58,8$ of caregivers $(23.5 \%)$ are parents, 8 $(23.5 \%)$ are siblings or children, and $18(53 \%)$ are spouses of the patients. $29.7 \%$ of 37 healthy controls who demographically matched the caregivers have an average age of $37.11 \pm 10.04$. Demographical properties of the groups are presented in the following table (Table 1).

\begin{tabular}{|c|c|c|c|}
\hline & Caregivers $(n=34)$ & Controls $(n=37)$ & p \\
\hline Age $(\text { Years })^{*}$ & $41.76 \pm 14.58$ & $37.11 \pm 10.04$ & 0.138 \\
\hline $\begin{array}{l}\text { Gender }(\%)^{* *} \\
\text { Female } \\
\text { Male }\end{array}$ & $\begin{array}{l}41.2 \% \\
58.8 \%\end{array}$ & $\begin{array}{l}29.7 \% \\
70.3 \%\end{array}$ & 0.313 \\
\hline $\begin{array}{l}\text { Marital Status }(\%)^{* \star} \\
\text { Never Married } \\
\text { Married } \\
\text { Divorced }\end{array}$ & $\begin{array}{l}29.4 \% \\
61.8 \% \\
8.8 \%\end{array}$ & $\begin{array}{l}37.4 \% \\
57.2 \% \\
5.4 \%\end{array}$ & 0.690 \\
\hline $\begin{array}{l}\text { Financial Status }(\%)^{\star *} \\
\text { Poor } \\
\text { Middle Class } \\
\text { Upper-Middle Class } \\
\text { Rich }\end{array}$ & $\begin{array}{l}14.7 \% \\
58.8 \% \\
14.7 \\
11.8 \%\end{array}$ & $\begin{array}{l}\% 4.3 \% \\
32.1 \% \\
40.4 \% \\
23.2 \%\end{array}$ & 0.023 \\
\hline Education (years) ${ }^{*}$ & $8.18 \pm 3.67$ & $9.78 \pm 4.12$ & 0.111 \\
\hline $\begin{array}{l}\text { Working Status }(\%)^{* *} \\
\text { Working }\end{array}$ & $47.1 \%$ & $53.2 \%$ & 0.556 \\
\hline
\end{tabular}

Table 1: Socio-demographical Features ${ }^{\star}$ Student $t$ Test, ${ }^{* *}$ Chi-square Test.

Comparison of clinical variables between the groups is shown in Table 2: It has been observed that both the state and trait anxiety score averages of caregivers are higher. There is no significant difference between average depression scores of the groups. As for personality traits, average endurance scores are statistically higher in the patient relatives group, yet other aspects show no significant differences.

\begin{tabular}{|l|l|l|l|l|}
\hline & Caregivers & Controls & $\mathbf{t}$ & $\mathbf{P}$ \\
\hline STAIX-I & $41.59 \pm 10.70$ & $33.47 \pm 5.82$ & 8.65 & $<0.001$ \\
\hline STAIX-II & $44.59 \pm 9.22$ & $37.04 \pm 5.33$ & 10.12 & $<0.001$ \\
\hline HDRS & $2.91 \pm 1.82$ & $2.74 \pm 2.30$ & 0.351 & 0.727 \\
\hline TCI Subscale & & & & \\
\hline Novelty Seeking & $17.44 \pm 3.76$ & $19.11 \pm 5.51$ & -1.639 & 0.104 \\
\hline Harm Avoidance & $16.53 \pm 5.00$ & $16.36 \pm 7.90$ & 0.118 & 0.906 \\
\hline
\end{tabular}




\begin{tabular}{|l|l|l|l|l|}
\hline $\begin{array}{l}\text { Reward } \\
\text { Dependence }\end{array}$ & $14.74 \pm 2.55$ & $14.43 \pm 3.26$ & 0.503 & 0.616 \\
\hline Persistence & $5.29 \pm 1.61$ & $4.47 \pm 2.09$ & 2.116 & 0.036 \\
\hline Self Directedness & $28.41 \pm 5.97$ & $29.59 \pm 7.21$ & -0.862 & 0.390 \\
\hline Cooperativeness & $30.59 \pm 5.48$ & $30.57 \pm 5.12$ & 0.015 & 0.988 \\
\hline $\begin{array}{l}\text { Self } \\
\text { Transcendence }\end{array}$ & $19.06 \pm 5.61$ & $20.79 \pm 5.33$ & -1.617 & 0.108 \\
\hline
\end{tabular}

Anxiety Inventory, HDRS; Hamilton Depression Rating Scale, TCI; Cloninger's Temperament and Character Inventory.

Analyses for correlation between clinical variables are shown in Table 3. While the state and trait anxiety scores are correlated with personality traits, depression scores reveal no correlation with any variable.

Table 2: Comparison of the groups according to STAIX-I and II, HDRS, TCI scores, STAIX-I and II; Spielberger'sState and Trait

\begin{tabular}{|c|c|c|c|c|c|c|}
\hline \multirow[t]{2}{*}{ TCI Subscales } & \multicolumn{2}{|c|}{ STAIX-I } & \multicolumn{2}{|c|}{ STAIX-II } & \multicolumn{2}{|c|}{ HDRS } \\
\hline & $r$ & $\mathrm{p}$ & $r$ & $\mathrm{p}$ & $r$ & $\mathrm{p}$ \\
\hline Novelty Seeking & 0.08 & 0.64 & -0.02 & 0.90 & -0.06 & 0.73 \\
\hline Harm Avoidance & 0.64 & $<0.001$ & 0.62 & $<0.001$ & 0.24 & 0.18 \\
\hline Reward Dependence & -0.22 & 0.21 & -0.24 & 0.17 & -0.13 & 0.46 \\
\hline Persistence & 0.27 & 0.13 & 0.37 & 0.03 & 0.02 & 0.91 \\
\hline Self Directedness & -0.58 & $<0.001$ & -0.58 & $<0.001$ & -0.31 & 0.07 \\
\hline Cooperativeness & -0.33 & 0.06 & -0.15 & 0.39 & -0.32 & 0.07 \\
\hline Self Transcendence & 0.44 & 0.01 & 0.47 & 0.005 & 0.13 & 0.48 \\
\hline
\end{tabular}

Table 3: Correlations between TCI and STAIX-I / II and HDRS. TCI: Cloninger's Temperament and Character Inventory, STAIX-I and II; Spielberger's State and Trait Anxiety Inventory, HDRS; Hamilton Depression Rating Scale.

\section{Discussion}

Although the key role of caregivers in the follow-up and treatment of schizophrenia is widely accepted, the number of studies conducted in Turkey is not consistent with the significance of this topic. In our study, the correlation between the anxiety conditions of caregivers and personality traits that may interact with anxiety will be discussed in order to contribute to researches in this field.

In this study, anxiety scores of caregivers were evaluated by means of the Staix 1 and 2 scales based on the presumption that two different anxiety conditions may be identified during hospitalization and home treatment. At the end of the study, it was observed that Spielberger's state and trait anxiety scores were higher in caregivers compared to the healthy control group. In two different studies where anxiety and depressive conditions of caregivers for schizophrenia patients who receive long-term treatment were assessed, it was reported that the anxiety and depression scores of patient relatives are higher than the healthy controls $[15,16]$. Gibbons et al. [16] reported that the level of psychological stress experienced by caregivers was inversely proportional to the duration of the disease. In our study, average care giving period was found to be $8.00 \pm 5.49$ years. This leads to the fact that during the initial ten years of the disease, patient relatives cannot adequately cope with anxiety and this is a major factor of subjective burdens related with care giving. Aydın et al. [17] found higher depression and anxiety levels in caregivers compared to the controls. They reported a positive correlation between the daily care giving duration with depression and anxiety levels of caregivers. In studies conducted with caregivers of chronic patients other than those suffering from psychiatric disorders, high anxiety and depression scores were reported. In their study with caregivers of oncological patients receiving radiotherapy, Dunn et al. [18] found that anxiety and depression symptoms in young, female caregivers accompanied with children at home are more frequent and severe. Becoming a caregiver is a non-optional or an unplanned condition. Therefore, adaptation to this situation of care giving starts within the following period of illness [2]. In their study, Gülseren et al. [19] reported that family members who spend the longest period with schizophrenia patients feel themselves confused between the real world and imaginary world of the patients and thus it could be a reason for the anxiety of caregivers. In our study, high anxiety scores should be evaluated according to adaptation efforts against stigmatization and exclusion from the society and corruption of harmony in social relations of caregivers of schizophrenia patients.

Another major consideration while analysing the correlation between caregiver and anxiety level is the impact of personality on the anxiety response to the stressor. According to our literature review, there is no study examining the correlation between anxiety or depression levels in the relatives or caregivers of schizophrenia patients and their personality traits. Furthermore, in some studies it was found that HA is higher among the relatives of schizophrenia patients compared with the control group [20,21]. Sim et al. [21] showed that such high scores increase particularly with higher genetic tendency to schizophrenia. Bora and Veznedaroğlu [22] found higher $\mathrm{HA}$ in the relatives of schizophrenia patients with schizotypal nature compared with the controls. However, HA in non-schizotypal relatives was found similar compared to the controls. In our study, comparisons to analyse the correlation between the sub dimensions of 
Page 4 of 5

STAIX-I and TCI among the relatives of schizophrenia patients revealed no significant differences between temperament-character dimension scores, except for P, HA, ST and SD. P, HA and ST have positive correlation with STAIX-I, while SD has a statistically negatively significant correlation. Cloninger [23] described HA as a genetic condition of inhibiting the behaviour as a response to the stimuli of punishment or disappointment. He further explained " $\mathrm{HA}$ is also observed as an unidentified fear, timidness and social disability, passive avoidance of problems or threat, quick exhaustion and pessimistic anxiety for problems that do not concern other people. Adaptive benefit of $\mathrm{HA}$ is precaution and careful planning in case of a threat" [23]. Smith et al. [20] found higher SD in the relatives of schizophrenia patients compared with the control group. Bora and Veznedaroğlu [22] showed that such high scores are valid for nonschizotypal relatives. Cloninger et al. [24] reported that SD is associated with both depression and anxiety. Furthermore, SD was found to be correlated with all classifications of personality disorders [25]. In summary, low SD suggests a difficulty underlying the entire mental disorders or a general tendency. A self-directed person can be described as self-confident, reliable, skilled, focused and at peace with himself. The greatest advantage of self-directed individuals is being realistic and influential. Thus this ensures that they can adapt their behaviours to reach the target they aim. Individuals with poor selfdirectedness scores are accusing, help-seeking, irresponsible, unreliable and reactive [23]. In studies that compare relatives of schizophrenia patients with controls, both higher [26] and lower [27] ST values compared to the controls were reported. According to Cloninger, ST indicates the person perceives himself/herself as a part of the whole universe. Self-transcendent individuals are equitable, empathetic, plain and humble. Individuals with lower scores ofselftranscendence tend to be practical, unbiased, materialist and showy [23]. Considering this data, it may be argued that since caregivers for schizophrenia patients are supportive, devoted and altruistic, their anxiety scores are high. Such persons do not experience anxiety because they feel uncertain or pessimistic about their patients, rather they are anxious because the patients do not deserve their current personal / social position.

The analysis between all sub-dimensions of STAIX-II and TCI revealed a positive correlation with $\mathrm{HA}, \mathrm{P}$ and ST and a statistically negatively significant correlation with SD. For Cloninger [9,23], P with no identified correlation with STAIX-I but positively correlated with STAIX-II reflects the genetic disposition for maintaining the behaviour despite occasional strain, fatigue and obstruction. Individuals with high persistency work hard, show efforts and maintain an ambition for superior achievement. Such ambition reflects their tendency to react with an excessive effort to be rewarded and to challenge fatigue or obstructions. Individuals with lower persistency are lazy, inactive, indecisive and untidy, they do not work hard for better achievement and tend to give up easily [23]. Though such individuals exhibit consistent performance for care giving, this may suggest a consistent anxiety as well.

Comparisons between the groups in our study have not revealed significant differences between caregivers of schizophrenia patients and control groups in terms of HA, SD and ST temperament-character dimensions. The underlying reason might be that, while the caregivers of schizophrenia patients in above mentioned studies are represented by genetically related people, more than half of caregivers in our study (53\%) are composed of spouses that have no genetic ties with the patient. This may serve as a reflection of the social structure allowing patients with schizophrenia to get married and maintain their marriage.

\section{Acknowledgements}

The authors state no conflict of interest. The study was not supported by any funding sources. This study is published in the abstract book of the 5th International Congress on Psychopharmacology \& 1st International Symposium on Child and Adolescent Psychopharmacology as a poster abstract.

\section{References}

1. Duman ZÇ, Bademli K (2013) Families of Chronic Psychiatric Patients: A Systematic Review Current Approaches in Psychiatry 5: 78-94.

2. Atagün Mİ, Balaban ÖD, Atagün Z, Elagöz M, Özpolat AY (2011) Caregiver Burden in Chronic Diseases. Current Approaches in Psychiatry 3: 513-552.

3. Brown S, Birtwistle J (1998) People with schizophrenia and their families. Fifteen-year outcome. Br J Psychiatry 173: 139-144.

4. Holzinger A, Kilian R, Lindenbach I, Petscheleit A, Angermeyer MC (2003) Patients' and their relatives' causal explanations of schizophrenia. Soc Psychiatry Psychiatr Epidemiol 38:155-162.

5. Saunders JC, Byrne MM (2002) a thematic analysis of families living with schizophrenia. Arch Psychiatr Nurs 16: 217-223.

6. Hinrichsen GA, Lieberman JA (1999) Family attributions and coping in the prediction of emotional adjustment in family members of patients with first-episode schizophrenia. Acta Psychiatr Scand 100:359-366.

7. Hooley JM, Campbell C (2002) Control and controllability: beliefs and behaviour in high and low expressed emotion relatives. Psychol Med 32: 1091-1099.

8. Angermeyer MC, Schulze B, Dietrich S (2003) Courtesy stigma--a focus group study of relatives of schizophrenia patients. Soc Psychiatry Psychiatr Epidemiol 38: 593-602.

9. Cloninger CR, Svrakic DM, Przybeck TR (1993) A psychobiological model of temperament and character. Arch Gen Psychiatry 50: 975-990.

10. Köse S, Sayar K, Kalelioğlu Ü, Aydın N, Ak İ, et al. (2004) Temperament and Character Inventory (Turkish TCI): Validity, Reliability and Factor Structure. Clinical Psychopharmocology Bulletin (In Turkish) 14: 107-131.

11. Williams JB (1988) a structured interview guide for the Hamilton Depression Rating Scale. Arch Gen Psychiatry 45: 742-747.

12. Akdemir A, Örsel S, Dağ İ, Türkçapar H (1996) Validity, Reliability and The Clinical Use of Hamilton Depression Rating Scale. Journal of Psychiatry Psychology Psychopaharmaclogy (In Turkish) 4: 251-259.

13. Spielberger C, Gorsuch RL, Lushene RD (1970) Manual for the state-trait anxiety inventory. Palo Alto, CA.: Consulting Psychologists Press.

14. Öner N, Lecompte A (1985) State-Trait Anxiety Inventory Handbook. Istanbul: Boğaziçi University Publishers (In Turkish).

15. Oldridge ML, Hughes IC (1992) Psychological well-being in families with a member suffering from schizophrenia. An investigation into longstanding problems. Br J Psychiatry 161: 249-251.

16. Gibbons JS, Horn SH, Powell JM, Gibbons JL (1984) Schizophrenic patients and their families. A survey in a psychiatric service based on a DGH unit. Br J Psychiatry 144: 70-77.

17. Aydın A, Eker SS, Cangür Ş, Sarandöl A, Kırlı S (2009) the link between burden level of the caregivers of schizophrenic patients and sociodemograpic variables and charecteristics of schizoprenia. Journal of Neuropsychiatry Archive (In Turkish) 46: 10-14.

18. Dunn LB, Aouizerat BE, Cooper BA, Dodd M, Lee K, et al. (2012) Trajectories of anxiety in oncology patients and family caregivers during and after radiation therapy. Eur J Oncol Nurs 16: 1-9.

19. Gülseren L, Turgut S, Yaprak S, Kültür S (1999) The Proceess of Psychodramatic Group Therapy with The Families of The Patients Who Has Diagnosed with Schizophrenia. The Jornal of Turkish Psychiatry 10: 325-331. 
Citation: Yilmaz ED, Deveci E, Kadioglu H, Gençer AG, Ünal O, et al. (2014) Correlation between Anxiety and Personality in Caregivers for Patients with Schizophrenia. J Psychiatry 17: 130. doi:10.4172/2378-5756.1000130

Page 5 of 5

20. Smith MJ, Cloninger CR, Harms MP, Csernansky JG (2008) Temperament and character as schizophrenia-related endophenotypes in non-psychotic siblings. Schizophr Res 104: 198-205.

21. Sim M, Kim JH, Yim SJ, Cho SJ, Kim SJ (2012) Increase in harm avoidance by genetic loading of schizophrenia. Compr Psychiatry 53:372-378.

22. Bora E, Veznedaroglu B (2007) Temperament and character dimensions of the relatives of schizophrenia patients and controls: the relationship between schizotypal features and personality. Eur Psychiatry 22:27-31.

23. Cloninger CR (1987) A systematic method for clinical description and classification of personality variants. A proposal. Arch Gen Psychiatry 44 573-588.
24. Cloninger CR, Bayon C, Svrakic DM (1998) Measurement of temperament and character in mood disorders: a model of fundamental states as personality types. J Affect Disord 51: 21-32.

25. Svrakic DM, Whitehead C, Przybeck TR, Cloninger CR (1993) Differential diagnosis of personality disorders by the seven-factor model of temperament and character. Arch Gen Psychiatry 50: 991-999.

26. Margetic BA, Jakovljevic M, Ivanec D, Margetic B (2011) Temperament, character, and quality of life in patients with schizophrenia and their first-degree relatives. Compr Psychiatry 52:425-430.

27. Gonzalez-Torres MA, Inchausti L, Ibanez B, Aristegui M, FernandezRivas A, et al. (2009) Temperament and character dimensions in patients with schizophrenia, relatives, and controls. J Nerv Ment Dis 197: 514-519. 